\title{
IF YOU ARE FEELING CONFIDENT ENOUGH, DO NOT HESITATE TO REVEAL WHO YOU REALLY ARE: \\ EXTENSION OF BAKER, HONEA, AND RUSSELL (2004)
}

A Thesis
presented to
the Faculty of the Graduate School
at the University of Missouri-Columbia
In Partial Fulfillment
of the Requirements for the Degree
Master of Arts
KYUNGKU LEE
Dr. Glen Cameron, Thesis Supervisor
MAY 2017


C Copyright by Kyungku Lee 2017

All Rights Reserved 
The undersigned, appointed by the dean of the Graduate School, have examined the thesis entitled

IF YOU ARE FEELING CONFIDENT ENOUGH, DO NOT

HESITATE TO REVEAL WHO YOU REALLY ARE:

EXTENSTION OF BAKER, HONEA, AND RUSSELL (2004)

presented by Kyungku Lee,

a candidate for the degree of Master of Arts

and hereby certify that, in their opinion, it is worthy of acceptance.

Professor Glen Cameron

Professor Margaret Duffy

Professor Brad Best

Professor Benjamin Warner 


\section{ACKNOWLEDGEMENT}

Foremost, I would like to thank God for helping me to finish my thesis. You have been truly lamp to my feet and light for my path. I shall never forget the fact that you always make my path.

I would also like to thank Dr. Cameron adopting me as his student. Although I

often teased him by visiting his office, he not only always welcomed me but also gave me sincere advices on thesis paper. It would have been much tough semester without Dr. Cameron. Without your help, I wouldn't be even able to dream to finish my Master's thesis. It was really fun and helpful to have a conversation with you Dr. Cameron! I will never forget all the support and encouragement you gave me throughout the semester.

Lastly, I want to thank the support from my family. Mom, I really appreciate your encouragement and pray. Without your pray, I wouldn't be able to finish this journey. And dad, thank you for supporting me both financially and mentally. All the conversation we had in previous semester not only helped me to grow but also relieved my stress. My only and beloved sister, Hyojin, I truly appreciate your pray and support. I am so lucky to have you as my sister. I love you all. 


\section{TABLE OF CONTENTS}

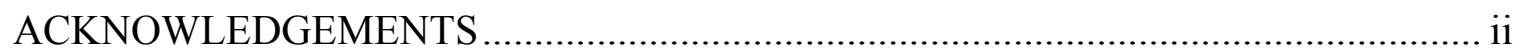

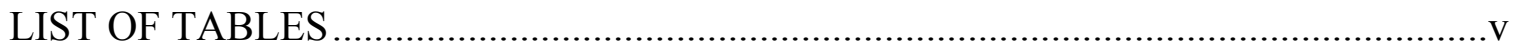

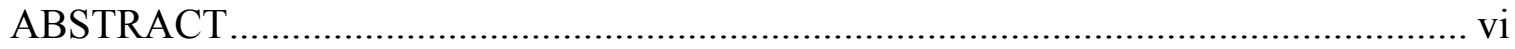

\section{CHAPTER}

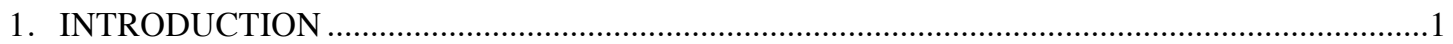

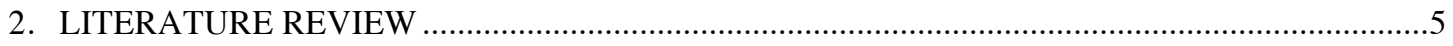

Narrative Advertising

Information Processing and Narratives

Different Definitions of Narrative

The Network Model of Memory

Prior Brand Attitude

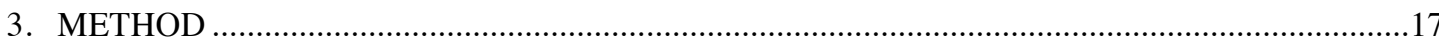

Design

Independent Variables

Dependent Variables

Stimuli

Participants

Procedure

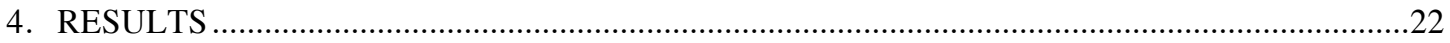

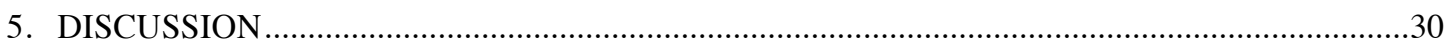

\section{APPENDIX}
A. ADVERTISEMENTS
B. LOGO
C. STUDY DESIGN 


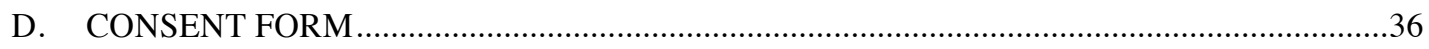

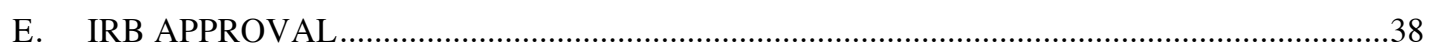

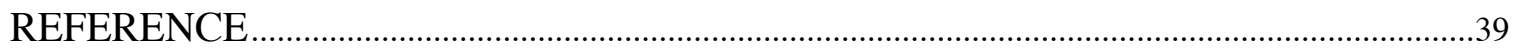




\section{LIST OF TABLES}

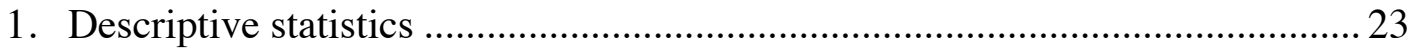

2. Dependent variable: Mean and standard deviation .......................................... 24

3. Summary of simple effects analyses for ad and brand attitudes and response latency by message type: Means and standard deviations ............................. 25

4. Summary of simple effects analyses for ad and brand attitudes and response latency by brand name placement: Means and standard deviations .................225

5. Message type by brand name placement: Means and standard deviations ........27

6. Summary of ANOVA for effects of ad type, brand name placement, and prior

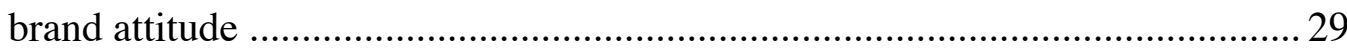




\begin{abstract}
Due to the competitive advertising environment, marketers have been employing different executional factors including humor and narrative feature within the advertising. Based on the Network of Model of Memory, Baker, Honea, and Russell (2004) examined whether the brand name placement influences on the way people perceive the advertising and brand information retention. As an extension of Baker et al.'s study, this study examines the role of narrative features within the advertising, prior attitude, and brand name placement. But the present findings are not consistent with Baker et al.'s study that early presentation of the brand name does not elicit better attitude toward the advertising, brand. Findings also show that there is no significant effect on memory retention.
\end{abstract}

Keywords: Brand name placement, prior attitude, narrative advertising, network model of memory 


\section{CHAPTER 1: INTRODUCTION}

Marketers spend billions of dollars on advertising to understand and change consumer behaviors. According to a 2014 report, advertising budgets have been increasing every year and are expected to reach $\$ 540$ billion globally in 2015 , which is $4.6 \%$ increase comparing to 2014 , because of competitive market circumstances (Sebastian, 2015). Although marketers allocate billions of dollars to their advertising budget, there is skepticism regarding the effectiveness of advertising (Sterling, 2015). Unlike the past belief that people engage with advertising and process information by thoroughly examining advertising claims, studies have revealed that many people rely on heuristic cues or are inattentive to advertising (Cacioppo, Petty, Kao, \& Rodriguez, 1986; Petty \& Cacioppo, 1986).

Additionally, studies have shown that even if people pay attention to advertising, there is no guarantee that advertising exposure can always influence consumers' purchase decisions. For example, a survey of people who watched Super Bowl ads in 2013 showed that consumers reported better recall of the ads after exposure to them, but that this did not actually motivate them to purchase the products. In fact, some of them reported that they did not even remember the brands that had been advertised or recall wrong brands that has not been advertised (Neff, 2014). Even if marketers spend colossal amounts of money on advertising, it is useless if consumers cannot recall the brand and its advertising information correctly.

Researchers point out that low advertising effectiveness is due to consumers' inattention to advertising, which leads to poor memory (Burke \& Srull, 1988). To improve consumers' attention, marketers have used different tactics, including emotional 
appeal and the elicitation of curiosity (Deighton, Romer, \& McQueen, 1989). Since the 1980s, humor in advertising has received attention among marketers, and the use of humor in advertising has increased substantially because of its benefits (Geuens, De Pelsmacker, \& Faseur, 2011). Humorous advertising has the ability to attract more attention than non-humorous advertising can (Weinberger \& Gulas, 1992). Therefore, many marketing practitioners and research executives prefer to include humor in their advertisements (Madden \& Weinberger, 1984).

In addition to increasing emotional appeal, researchers have taken further steps by employing narrative features within the advertising. Many scholars agree that narrative advertising is like a story-like format adverting (Escalas, 2004a, 2004b; Escalas, Moore, \& Britton, 2004). Unlike traditional advertising, which is also known as argumentative ad or product features ad, narrative advertising has a story plot that contains beginning, middle, and end (Escalas, 2004b). Although there is disagreement over what elements constitute narrative, for this study, narrative advertising contains two features: chronology (passage of time) and causality (cause and result) (Escalas, 1998, 2004a).

One of the reasons of increment of narrative advertising usage among practitioners is that narrative advertising has advantages over non-narrative advertising such as eliciting less counterarguments and negative cognitive responses (Brechman \& Purvis, 2015; Kim, Ratneshwar, \& Thorson, 2017). Although many of narrative advertising literatures illustrate that narrative advertising is an effective tool for consumer persuasion, it is difficult to directly infer that narrative advertising is always effective over non-narrative advertising at any circumstances.

Limited studies have examined whether effectiveness of narrative advertising 
would be affected by other features such as message frame, situation feature, and individual differences. However, none of the studies have looked how individuals' prior attitude would affect on interpretation of narrative advertising. Also, limited studies have taken situational features of advertising into account.

Many of the advertising don't reveal its brand name without revealing any signs or indication of the brand until the end of the advertising. This is because practitioners believe that revealing brand name could interfere one's immersion into the story and elicit less curiosity (Baker, 2003; Baker, Honea, \& Russell, 2004). Although studies by Baker and his colleagues prove that revealing brand name in the beginning of the advertising increase both attitude toward the ad, brand and strengthen association between the advertising information and the brand, many of advertising still shun to present the brand name in the beginning of the advertising. Furthermore, the trend of avoiding brand name placement in the beginning of the advertising could also be found in narrative advertising. Therefore, since Baker and his colleagues did not specifically examine how narrative advertising would interact with the brand name placement, this study will test on how brand name placement influence on effectiveness of narrative advertising.

In addition to situational feature, this study also aims to examine whether individual differences influence on effectiveness of narrative advertising. Previous studies argue that individual difference affects one's immersion into the advertising. However, none of the studies have examined whether prior brand attitude change the direction of evaluation. For example, Chattopadhyay and Basu (1990) illustrate that although humor ad is mostly known as a powerful tool to persuade consumers, some 
people reported negative attitude and developed more counterarguments depending on their prior brand attitude.

For these reasons, this study focuses on examining how prior attitude in the narrative advertising influence on directionality of advertising evaluation. Additionally, this study aims to extend previous study by Baker, Honea, and Russell (2004) by examining how brand name placement influences on individual's interpreting narrative advertising. 


\section{CHAPTER 2: LITERATURE REVIEW}

\section{Narrative Advertising}

Scholars have paid attention to the narrative process because of the increase in its use across the mass-communication field. Narrative features can be easily found in health communication, social media, and advertising. Employing narrative advertising has become a common practice among marketers, and the reliance on narrative advertising has increased. According to Escalas (1998), one-fourth of television ads contain narrative features. Moreover, through content analysis, Brechman and Purvis found that almost half of the advertising in 2011 and that of the 2012 Super Bowl used narrative advertising.

Most scholars agree that narrative advertising is defined as having a format that resembles a story whereas non-narrative advertising can be defined as having an argumentative format (Brechman \& Purvis, 2015; Chang, 2009; Escalas, 2004b; Kim, Ratneshwar, \& Thorson, 2017). Narrative advertising, which has multiple field marks such as story-driven structuring and dramatic elements, delivers information through plot (Brechman \& Purvis, 2015; Escalas, 2004a, 2004b; Green \& Brock, 2000; Green, Brock, \& Kaufman, 2004). In this sense, narrative advertising shares similar traits with fearappeal advertising and humor advertising. This is because narrative advertising also relies on electing emotion from consumers rather than triggering logic. However, narrative advertising is distinct from the other two types of advertising because it delivers messages that have clear plots and tries to immerse consumers into the plots.

People sometimes experience the sensation of losing a sense of the world around them when they are highly focused on reading a novel. In fact, when people are 
immersed in a story, they even tend to forget about the passage of time. People who are empathetically connected with a protagonist even cry for the protagonist when he or she faces struggles or death in a story. Such experiences can also occur when someone watches a film, or has a similar immersive experience with media. The process of immersing oneself into the story and vicariously experiencing things through a narrative is known as transportation (Escalas, 2004a; Green \& Brock, 2000, 2004). According to Green and Brock, transportation is not limited to reading written material; listeners, viewers, or anyone who is exposed to narrative information has the potential to experience transportation.

Once people are immersed into a story, they change their beliefs and attitudes toward it—not because of their experience, prior knowledge, or logical thinking, but because they are empathetically attached to a character and the verisimilitudinous world the character inhabits (Escalas, 2004a, 2004b; Green \& Brock, 2000; Green et al., 2004). Scholars have found that when people are immersed into a narrative, they tend to reduce negative cognitive responses toward what they are experiencing, are less likely to disbelieve the narrative or form counterarguments against it, and begin to associate the narrative with their real-life experiences (Chang, 2009, 2013, Escalas, 2004b; Kim et al., 2017) In addition, narrative advertising elicits fewer counterarguments, more positive attitudes toward advertising, better attitudes and credibility toward brands, and more positive cognitive responses among consumers (Brechman \& Purvis, 2015; Chang, 2009; Escalas, 2004b; Kim et al., 2017).

Meanwhile, nonnarrative advertising, which is also known as traditional advertising, delivers plain messages and mainly focuses on stating the benefits of and 
providing overall information about products (Chang, 2009). In other words, nonnarrative advertising requires logical thinking from consumers to process messages. Unlike in narrative advertising, when people process non-narrative advertising, they tend to have counterarguments toward the claims that are made by ads (Chang, 2009; Deighton, Romer, \& McQueen, 1989; Escalas, 2004b).

The preference of narrative advertising over non-narrative advertising stems from the former's advantages over the latter. Its advantage is derived from its structure (Chang, 2009). According to Schank and Abelson (1995), people tend to memorize acquired social knowledge in a "story" format. In other words, we not only organize our experiences in a narrative format but also create brief stories when faced with puzzling information (Fiske, 1993). Because of these distinct human characteristics and the ways in which they explicitly contribute to how people interact with media, scholars should pay more attention to narrative advertising.

Therefore following hypothesis is provided:

- H1: Participants with narrative advertising would report more positive attitude toward the ad and more positive attitude toward the brand comparing to nonnarrative ad.

\section{Information Processing and Narratives}

Lang $(2000,2006)$ argued that human beings have limited cognitive resources for information processing that can be allocated for processing mediated messages. According to Lang (2000), message processing involves three subprocesses: encoding, storage, and retrieval. During the encoding process, people form mental representations

of the stimuli - although not exact copies — through both controlled and automatic 
processing. The quality of information processing depends on how many cognitive resources are allocated to each of the three subprocesses throughout message processing (Lang, 2000). For example, when a person reads a health-related article that is difficult to comprehend, more cognitive resources would be allocated to encoding. When more cognitive resources are allocated to encoding, fewer resources would be allocated to the other two subprocesses, which would eventually lead to failure of memory retention and retrieving information.

A similar phenomenon could occur when people encounter advertisements. In addition to retaining information from advertisements, people first need to interpret the messages and retrieve past information to figure out whether the claims in the advertisements are true. If the advertising is difficult to comprehend because of excessive creativeness or complex structuring, more cognitive resources will be allocated toward encoding the information and fewer to retaining it. This could result in poor recall of the information after exposure to advertisements.

In addition to the content of an advertisement, different executional cues and features within the advertisement influence how people process the information (Yoon, Bolls, \& Lang, 1998). For example, Lang, Geiger, Strickwerda, and Summer (1993) examined structural features in television messages that can influence people's attention, capacity, and memory of visual and audio information. Lang and her colleagues found that participants who were exposed to scene cuts related to scenes demonstrated better memory for messages compared with those who encountered information that was provided after unrelated cuts. They argued that even if both unrelated and related cuts elicit information processing, the amount of information that people retain differs 
depending on how the messages are designed.

To improve advertising effectiveness, marketers have employed different executional cues, such as humor and warmth. In addition, marketers have been employing different formats of advertising including humorous and narrative ads (Deighton, Romer, \& McQueen, 1989). Although previous literature illustrated that narrative advertising induced more positive attitudes toward a brand and advertising, empirical data have not yet shown whether narrative advertising also helps consumers retain information from an advertising. One study by Chang (2009) found that when people read narrative editorial content and were subsequently exposed to a narrative ad, they tended to evaluate the brand and ad less positively compared with people who read fact-based articles. This study illustrated that even though narrative ads induce positive evaluations, more cognitive resources are required to process the information.

Therefore, the current study aims to examine whether narrative advertising could help people encode and retrieve ad and brand information in addition to improving evaluation of ad and brand attitude.

\section{Different Definitions of "Narrative"}

Narrative advertising was introduced more than 20 years ago, but the definition of the term "narrative" is still a controversial issue among scholars of marketing (Brechman \& Purvis, 2015; Kim et al., 2017). They have still not reached an agreement on which features that constitute a narrative. Each scholar employs his or her own definition of narrative in his or her study. For example, Deigthon, Romer, and McQueen (1989) labeled narrative advertising as "drama advertising" in their study. They distinguish advertising into two broad categories: argument advertising and drama advertising. 
Additionally, Deighton et al. stated that drama advertising contains character, plot, and no narration within ta story. They also differentiate drama advertising from story advertising depending on the existence of a narrator in an ad. Although they define drama advertising, they do not specify which features should be contained within the plot for it to be considered a "drama."

According to Bruner (1990), there are four elements of narrative structures, but Escalas (1998) argued that a narrative is "one or more episodes consisting of actors engaged in actions to achieve goals. Sequence initiated by some event and action results in outcome" (p. 273). Escalas (1998, 2004a) also included two important elements of narrative in this definition: causality and chronology. Chronology indicates that a story has a beginning, middle, and end, while causality indicates that a story has a cause and effect. For example, if the protagonist of a story loses his/her parents because of a terrorist attack (cause), he/she swears to find the terrorists and avenge them (effect). Even though many advertisements have plots, not all of them contain these two features. Recent research conducted by Kim et al. (2017) defined narrative advertising as a plot that contains "five Ws (when, what, why, who, where) and an H (how)." Even though Kim et al. listed different elements that constituted a narrative, they, like other researchers, noted the importance of chronology. However, for the purpose of this study, I define narrative advertising as advertising that has plot, which specifically contains chronology and causality. Additionally, nonnarrative advertising is defined as advertising that does not contain plot or story. More specifically, nonnarrative advertising focuses on delivering product information directly to consumers by providing arguments or lectures (Chang, 2009) 


\section{The Network Model of Memory}

Baker (2003) found that many advertisements do not reveal the brand's name until the very end of the advertisement. Baker et al. (2004) found that practitioners and creative directors prefer not to reveal the brand name at the start of the ad. The primary reason they avoid placing the brand name at the beginning of the ad is to elicit curiosity so that people stay focused until the very end. Additionally, they fear that revealing the brand name at the start of the ad could interrupt consumers' engagement with the ad (Baker, Honea, \& Russell, 2004). Practitioners also believe that stating the brand in the beginning of advertising could decrease curiosity. As Baker et al.'s interviews illustrated, only a small percentage of advertisers reveal the brand name at the start of the ad. Although this claim seems logical, there is currently not enough empirical data to support the notion that placing the brand name at the start of the ad either increases curiosity or negatively affects advertising effectiveness. However, revealing the brand name at the end of the ad is the opposite of what a theory suggests.

Anderson (1983) argued that we do not lose information and data from our brains, but one of the reasons that we cannot retrieve it is that the "trace" has decayed. According to spreading activation theory (SAT), when people encode information, there is a chance that transient information transforms into a long-term memory trace (Roediger III, Balota, \& Watson, 2001). Once a trace is established, the strength of the trace and the items associated with it can either be improved or decayed through subsequent learning or repetition. Without repetition, the associated nodes gradually decay, and it takes a person more time to retrieve information (Fazio, 1990).

Once the incoming information activates the node, it spreads throughout the 
network, and activation gradually decreases as the distance between the hub node and node increases (Collins \& Loftus, 1975). For example, if someone thinks of "Starbucks," this can automatically activate another node such as "latte" "Americano." As the person repeatedly thinks more about "Starbucks," "Americano," and "latte," the connections between the associated nodes will become stronger. Furthermore, not only does the trace between the nodes fade away over time, but the intervention of other information can also result in decay (Anderson, 1983). Therefore, in a competitive market environment, where people are exposed to 300 to 600 ads per day, they are more likely to forget the information in the ads (Burke \& Srull, 1988).

People's ability to recall ads and brand information is also affected by the number and variety of competitors' ads (Burke \& Srull, 1988; Keller, 1987; Kent \& Allen, 1994). Burke and Srull (1988) pointed out that the interference of competitive advertising leads to inattention to advertising among consumers, which leads to poor memory of advertising information. Additionally, competitive brands have a detrimental effect on consumers' ability to not only remember advertising from the past but also learn brand information in future advertising. Hence, if they do not build a strong link between the advertising and the brand, consumers are more likely to recall inaccurate advertising information or not remember it all (Burke \& Srull, 1988).

Based on SAT, Baker (2003) investigated whether or not brand name placement influences association between advertising and the brand among consumers; he found that if the brand name is placed at the start of the ad, this activates the node, and subsequent advertising information is then associated with the brand node. This creates a stronger association between the ad and brand than it would if the brand name had been 
placed at the end of the ad. In this case, there would be much less time for the consumers to build an associative link between the brand and ad. Furthermore, in this scenario, right after the brand name was provided, another ad would be immediately presented to consumers, which could impede their creation of a link and lead to them making a false association.

Baker et al. (2004) found that revealing the brand name at the start of an ad improves consumer perception of a brand and leads to better brand recognition among consumers after exposure to the ad. However, their studies mainly focused on traditional advertising. Rather than solely measuring brand attitude to examine the strength of association, this study examines response latency as a measurement of the strength of association. Response latency measures how quickly people retrieve information from memory (Cameron \& Frieske, 1994). The faster the response is, the stronger the association between the stimuli and hub node is.

Therefore, this study aims to replicate the findings of Baker et al. (2004) using narrative advertising. Hence, the following hypotheses are presented:

- H2a: Response latency (brand name recognition), which indicates strength of advertisement and brand name association, will be shorter in non-narrative ad compared to narrative ad.

- H2b: Response latency (brand name recognition), which indicates strength of advertisement and brand name association, will be shorter for the early presentation of brand name to the late presentation.

\section{Prior Brand Attitude}

Prior brand attitude is determinant of evaluative directionality of information 
processing (Chattopadhyay \& Basu, 1990; Jin \& Villegas, 2007). Depending on prior brand attitude, the direction of information processing toward the advertising could be different. For example, if a person has positive attitude toward a brand, he or she is more likely to less critical of ads for that brand. On the other hand, if a consumer has negative prior brand attitude, the consumer would more likely evaluate the advertising unfavorably and critical of the advertising.

Previous literatures illustrate that prior brand attitude moderates people's evaluation toward the adverting and brand attitude after the exposure. Chattopadhyay and Basu (1990) found that even though humorous advertising is known as more effective tool to grab attention and increase persuasion than non-humorous advertising, the way people perceive the advertising is different depending on their prior attitude toward the advertising.

Chattopadhyay and Basu (1990) criticized in their study that many humorous advertising researchers make direct inferences that humor advertising is effective over non-humor advertising because it grabs more attention. However, they argue that even if humor advertising grabs more attention than non-humor ads, there is no guarantee that humor ad would be effective on people who already have negative brand attitude.

Similar to humor advertising, narrative advertising also relies on emotional appeal and shows greater effectiveness over non-narrative advertising. However, limited studies have examined individuals' traits on interpreting narrative advertising. Therefore, this study examines how prior brand attitude influences on interpreting narrative advertising.

As a study of Chattopadhyay and Basu (1990) illustrates, the effectiveness of brand-name placement would be also different depending on individual's prior brand 
attitude. For example, if a person's brand attitude toward Wal-Mart is unfavorable, the logo of the brand name in the beginning of the advertising would more likely to increase negative attitude toward advertising and brand. This is because when the person sees the logo in the beginning of the advertising, it would lead to activate unfavorable memory node. Once the node is activated, the negative prior attitude would stick with the advertising, which eventually could lead more negative attitude toward the advertising. Also, if the brand name is presented early in the advertising, it could hinder people from processing the story of the advertising because the prior attitude toward brand and the emotional tone of the messages from the advertising is inconsistent.

Although many studies illustrate that narrative advertising has clear advantages over non-narrative advertising, it is difficult to make direct inferences that narrative advertising would be always effective comparing to non-narrative advertising. And this effectiveness could be moderated by individual traits. Previous literatures examine whether individual differences elicit different level of transportability. These studies illustrate that effectiveness of narrative advertising could be divergent according to individual difference. Hence, other features such as prior brand attitude could also influence on directionality evaluation of narrative advertising. For instance, if a person has unfavorable attitude toward the brand, a person would less likely to be persuaded. This is because prior attitude brand could collide with emotional messages from the narrative advertising. Since the plot of the advertising is inconsistent with the prior brand attitude, it could eventually hinder one's evaluation of advertisement. Current study aims to find how prior attitude influences on interpretation of narrative advertising.

Therefore, following hypothesis is offered: 
- H3a: Narrative advertising would elicit more positive attitude toward ad and brand than non-narrative advertising when prior attitude toward the brand is positive and brand name is presented early in the advertising.

- H3b: Narrative advertising would elicit less positive attitude toward ad and brand than non-narrative advertising when prior attitude toward the brand is negative and brand name is presented early in the advertising. 


\section{CHAPTER 3: METHOD}

This study employs a 2 (ad type: narrative vs. non-narrative) x 2 (presentation type: early and late) between-subjects experimental design survey with prior attitude (high vs. low) as a moderator. The survey contains actual video commercials created by different companies. Based on two levels of each independent variable, the four conditions were created for this study: 1) narrative advertisement and early presentation of the brand name; 2) narrative advertisement and late presentation of the brand name; 3 ) non-narrative advertisement and early presentation of the brand name; and 4) nonnarrative advertisement and late presentation of the brand name.

\section{Participants}

Participants were sampled from students who enrolled in the spring semester of 2017 at a large research university in the Midwest. Participants were mainly recruited from 3 undergraduate courses and 1 undergraduate/graduate level course. Total of 335 participants finished the first part of the survey. 306 students subsequently participated the second part of the study and responses were stored in the online survey server. Among 306 students, 9 responses were deleted due to incomplete data and 4 responses were not used because their responses were not received within the acceptable time period. After deleting the incomplete data, 293 responses were valid.

\section{Stimuli Development}

In order to check variance in prior brand attitude, 30 participants were recruited via mTurk and evaluate 10 brands that are controversial in terms of their reputation. After the evaluation, only 1 brand (AT\&T) was selected and manipulated. For experimental 
stimuli, TV commercials from YouTube and Vimeo were used and edited through Final Cut Pro. Total of 7 different brands were selected and edited. For each condition, length of brand name presentation was controlled. Brand name was appeared 2 seconds at the beginning of the ad or end of the ad depending on the condition.

\section{Procedure}

This study was consisted of two parts: prior brand attitude measure and main experiment. Both parts of the survey were distributed through Qualtrics. Initially students were asked to send an email if they wish to participate the study. Once students sent an email, they received an invitation email that contained the instruction of the study and link for the survey. Once subjects opened the link, they were given an informed consent form and asked to read, and click the "next" button if they wish to participate the study. If participants chose 'no', they were routed to an alternative assignment option. Students who clicked 'yes', they could participate the first part of the study.

During the first part of the study, participants were measured their prior attitude toward the target brand. Participants evaluated total of 10 random brands with one target brand. Once they were done with evaluating the brands, they were asked to send confirmation email to participate the main study. The links for the main study were distributed 24 hours later in order to avoid any priming effect.

When participants agreed to join the main study, they were randomly assigned to one of four conditions (e.g. narrative with early presentation, non-narrative with early presentation, and etc.). Every participant was given total of 7 TV commercials with one manipulated commercial. After each commercial, participants were asked to report their 
overall attitude toward advertisements. Once participants finished watching all 7 commercials, they were given intervene task. They were asked to report their thoughts and suggestions to improve the presented advertisement. Right after the intervene task, participants were given brand recognition test. Participants saw following instruction in the recognition test section: In a moment, you will see different brands. If you find the brand that you previously saw in the advertising, click 'yes' as soon as you recognize it, if not please click 'no'. Recognition were coded dichotomously. Additionally, participants' response latency was measured. Lastly, they were asked to report their overall attitude toward the brand that they watched previously. See Appendix C for more details.

Once they finished the answering all the questions, they were automatically rerouted to a web page where they could report their names and student ID. Subjects were thanked and dismissed.

\section{Independent Variables}

\section{Brand Name Placement}

There was two levels, early and late presentation. In order to manipulate brand name placement, Final cut pro were used. Brand name was cropped from actual ads and the background music that went with the brand name was removed. Each brand name was shown 2 seconds either beginning of the advertisement or end of the advertisement.

\section{Message Type}

There was two levels, narrative advertising and nonnarrative advertising. Narrative advertising was selected based on a criterion Escalas (1998): chronology 
(passage of time) and causality (cause and result). In contrast, nonnarrative advertisement was mainly focusing on introducing features of products that did not have narrative features. Dependent Variables

\section{Attitude toward a) Advertising and b) Brand}

Attitude toward ad and attitude toward brand was measured by using a scale that was employed by Baker, Honea, and Russell (2004). After watching advertisements, the participants were asked to answer the following question: "My general opinion of the

advertising/brand is," "my overall impression of the advertising/brand is," and "my attitude toward advertising/brand," on 7-point scales ( $1=$ Very negative, $7=$ Very positive). Cronbach alpha reliability test for attitude toward advertising was .970 . Also, Cronbach alpha reliability test for brand attitude was .978 .

\section{Brand recognition (response latency)}

Each brand recognition questionnaire contained 6 different brands. After seeing the brands, the participants were asked to answer the following question: If the brand from the advertisement that you watched listed below, please select 'Yes'. If you do not see the brand listed please select 'No.' Participants were asked to click 'yes' if they found that the brand was shown previously. Response latency was measured through Qualtrics.

\section{Prior Brand Attitude}

Three questions were created to measure students' prior attitude toward the brand. The participants were asked to answer the question: "My general opinion of the advertising/brand is." "my overall impression of the advertising/brand is," and "my attitude toward advertising/brand," on 7-point scales ( $1=$ Very negative, $7=$ Very positive). 
Cronbach alpha reliability test for prior brand attitude was .939 . 


\section{CHAPTER 4: RESULTS}

\section{Descriptive Statistics}

Table 1 shows demographic statistics of participants. Among all participants, male respondents were 18.5 percent $(N=55)$ and female participants were 81.5 percent $(N=242)$. The majority of respondents were undergraduate students. To be more specific, there were 147 freshmen (49.5\%), 77 sophomores (25.9\%), 61 juniors (20.5\%), 10 seniors $(3.4 \%)$, and 2 graduates $(.7 \%)$.

Table 1 also illustrates how many students were allocated into one of four conditions. Among 293 participants, 50.2\% were exposed to a narrative ad $(N=147)$, $49.8 \%$ of participants were exposed to a non-narrative ad $(N=146), 49.8 \%$ of participants were exposed to early brand name placement $(N=146)$, and $50.2 \%$ of participants were exposed late brand name placement $(N=147)$

Additionally, table 1 shows that $24.9 \%$ of respondents were exposed narrative and early brand name placement $(N=73), 25.3 \%$ of respondents were exposed narrative and late brand name placement $(N=74), 24.9 \%$ of respondents were exposed non-narrative and early brand name placement $(N=73), 24.9 \%$ of respondents were exposed nonnarrative and late brand name placement $(N=73)$. 
Table 1. Descriptive statistics

\begin{tabular}{|c|c|c|}
\hline Variables & Count & Percent \\
\hline \multicolumn{3}{|l|}{ Gender } \\
\hline Male & 55 & 18.8 \\
\hline Female & 238 & 81.2 \\
\hline & 293 & $100 \%$ \\
\hline \multicolumn{3}{|l|}{ College year } \\
\hline Freshmen & 146 & 49.8 \\
\hline Sophomore & 76 & 25.9 \\
\hline Junior & 60 & 20.5 \\
\hline Senior & 9 & 3.1 \\
\hline Graduate & 2 & .7 \\
\hline & 293 & $100 \%$ \\
\hline \multicolumn{3}{|l|}{ Ad type } \\
\hline Narrative & 147 & 50.2 \\
\hline Nonnarrative & 146 & 49.8 \\
\hline & 293 & $100 \%$ \\
\hline \multicolumn{3}{|l|}{ Placement } \\
\hline Early & 146 & 49.8 \\
\hline Late & 147 & 50.2 \\
\hline & 293 & $100 \%$ \\
\hline \multicolumn{3}{|l|}{ Ad type and Placement } \\
\hline Narrative and Early & 73 & 24.9 \\
\hline Narrative and Late & 74 & 25.3 \\
\hline Nonnarrative and Early & 73 & 24.9 \\
\hline \multirow[t]{2}{*}{ Nonnarrative and Late } & 73 & 24.9 \\
\hline & 293 & $100 \%$ \\
\hline
\end{tabular}


Table 2. Dependent variable: Mean and standard deviation $(N=293)$

\begin{tabular}{lll}
\hline Variables & Mean & SD \\
\hline Attitude toward brand (AT\&T) $^{\mathrm{a}}$ & 5.05 & 1.32 \\
My general opinion of the brand is.. $^{\mathrm{b}}$ & 5.06 & 1.36 \\
My overall impression of the brand is.. $^{\mathrm{b}}$ & 5.06 & 1.32 \\
My attitude toward the brand is.. $^{\mathrm{b}}$ & 4.99 & 1.36 \\
Attitude toward advertising (AT\&T) $^{\mathrm{a}}$ & 5.16 & 1.32 \\
My general opinion of the advertisement is.. $^{\mathrm{b}}$ & 5.15 & 1.36 \\
$\quad$ My overall impression of the advertisement is.. & 5.18 & 1.35 \\
$\quad$ My attitude toward the brand is.. & 5.14 & 1.38 \\
Response latency & 7.24 & 3.77 \\
\hline
\end{tabular}

a. Attitude toward brand and advertising is average value after summing up each three questions.

b. Responses were coded $1=$ Very negative, $7=$ Very positive

As for the dependent variables, Table 2 shows means and standard deviation of each variable. Attitude toward brand was calculated as the average of three items, including general opinion $(M=5.06, S D=1.36)$, impression $(M=5.06, S D=1.32)$, attitude $(M=4.99, S D=1.36)$. Additionally, attitude toward advertisement was calculated as the average of three times, general opinion $(M=5.15, S D=1.36)$, impression $(M=5.18, S D=1.35)$, attitude $(M=5.14, S D=1.38)$.

\section{Main Effects}

Results are assessed by a series of 2 (ad type: narrative vs non-narrative) x 2 (brand name placement: early vs late) analysis of variance (ANOVAs). 
Table 3. Summary of simple effects analyses for ad and brand attitudes and response latency by message type: Means and standard deviations.

\begin{tabular}{|c|c|c|c|c|}
\hline \multirow[b]{2}{*}{$\begin{array}{l}\text { Dependent } \\
\text { variable }\end{array}$} & \multicolumn{2}{|c|}{ Narrative } & \multicolumn{2}{|c|}{ Non-narrative } \\
\hline & $M$ & $S D$ & $M$ & $S D$ \\
\hline Ad attitude & 5.68 & 1.32 & 4.63 & 1.10 \\
\hline Brand attitude & 5.14 & 1.24 & 4.96 & 1.39 \\
\hline Response latency & 7.69 & 3.84 & 6.79 & 3.65 \\
\hline
\end{tabular}

Table 4. Summary of simple effects analyses for ad and brand attitudes and response latency by brand name placement: Means and standard deviations.

\begin{tabular}{|c|c|c|c|c|}
\hline \multirow[b]{2}{*}{$\begin{array}{l}\text { Dependent } \\
\text { variable }\end{array}$} & \multicolumn{2}{|c|}{ Early } & \multicolumn{2}{|c|}{ Late } \\
\hline & $M$ & $S D$ & $M$ & $S D$ \\
\hline Ad attitude & 5.18 & 1.31 & 5.14 & 1.33 \\
\hline Brand attitude & 4.93 & 1.33 & 5.16 & 1.30 \\
\hline Response latency & 7.20 & 3.89 & 7.28 & 3.77 \\
\hline
\end{tabular}

As Table 5 shows, there was no significant difference among four conditions on response latency, $F(1,293)=1.41, p=.240$. Means and standard deviations were as follows: (a) narrative ad and early placement $(M=7.64, \mathrm{SD}=4.05)$; (b) narrative ad and late placement $(M=7.74, \mathrm{SD}=3.65)$; (c) non-narrative ad and early placement $(M=$ $6.76, \mathrm{SD}=3.69)$; (d) narrative ad and late placement $(M=6.82, \mathrm{SD}=3.62)$.

Also, there was no significant differences among four conditions on attitudes toward the brand, $F(1,293)=1.66, p=.176$. Means and standard deviations were as 
follows: (a) narrative ad and early placement $(M=4.93, \mathrm{SD}=1.40)$; (b) narrative ad and late placement $(M=5.34, \mathrm{SD}=1.02)$; (c) non-narrative ad and early placement $(M=$ $4.93, \mathrm{SD}=1.27)$; (d) narrative ad and late placement $(M=4.98, S D=1.51)$.

On the other hand, Table 5 shows that there is significant difference among conditions on attitudes toward the advertising. Means and standard deviations were as follows: (a) narrative ad and early placement $(M=5.62, S D=1.45)$; (b) narrative ad and late placement $(M=5.74, S D=1.20)$; (c) non-narrative ad and early placement $(M=$ $4.74, S D=.99)$; (d) narrative ad and late placement $(M=4.53, S D=1.10)$. Pairwise comparison showed that narrative advertising and early condition $(M=5.62)$ produced a significantly higher positive attitude toward the ad $(p<.001)$ than non-narrative ad with early placement $(M=4.74)$ and non-narrative ad with late placement $(M=4.53)$. In addition, narrative advertising with late placement $(M=5.74)$ also produced significantly higher positive attitude toward the ad $(p<.001)$ than non-narrative ad with early placement $(M=4.74)$ and non-narrative ad with late placement $(M=4.53)$.

However, there was no significant differences between narrative ad with early and late placement $(p=.543)$. Additionally, no significant difference was found between nonnarrative ad with early and late placement $(p=.309)$. 
Table 5. Message type by brand name placement: Means and standard deviations.

\begin{tabular}{|c|c|c|c|c|c|c|}
\hline \multirow[b]{2}{*}{$\begin{array}{l}\text { Dependent } \\
\text { variable }\end{array}$} & \multicolumn{3}{|c|}{ Narrative } & \multicolumn{3}{|c|}{ Non-narrative } \\
\hline & $\begin{array}{l}\text { Early } \\
\text { (SD) }\end{array}$ & $\begin{array}{l}\text { Late } \\
\text { (SD) }\end{array}$ & $F$ & $\begin{array}{l}\text { Early } \\
\text { (SD) }\end{array}$ & $\begin{array}{l}\text { Late } \\
\text { (SD) }\end{array}$ & $F$ \\
\hline Ad attitude & $\begin{array}{c}5.62 \\
(1.45)\end{array}$ & $\begin{array}{c}5.74 \\
(1.20)\end{array}$ & .38 & $\begin{array}{l}4.74 \\
(.99)\end{array}$ & $\begin{array}{c}4.53 \\
(1.10)\end{array}$ & 1.35 \\
\hline Brand attitude & $\begin{array}{c}4.93 \\
(1.40)\end{array}$ & $\begin{array}{c}5.34 \\
(1.02)\end{array}$ & 9.29 & $\begin{array}{c}4.93 \\
(1.27)\end{array}$ & $\begin{array}{c}4.98 \\
(1.51)\end{array}$ & .21 \\
\hline $\begin{array}{l}\text { Response } \\
\text { latency }\end{array}$ & $\begin{array}{c}7.64 \\
(4.05)\end{array}$ & $\begin{array}{c}7.74 \\
(3.65)\end{array}$ & .02 & $\begin{array}{c}6.75 \\
(3.70)\end{array}$ & $\begin{array}{c}6.82 \\
(3.62)\end{array}$ & .009 \\
\hline
\end{tabular}

\section{Hypotheses Testing}

The results of the analysis are reported in Table $6 . \mathrm{H} 1$ predicted that subjects who are exposed to narrative ad would evaluate the brand and the advertisement more positive than subjects with non-narrative ad condition. Consistent with prior research (Kim et al., 2017) , participants in the narrative ad condition reported higher positive ad attitude, $F(1,293)=52.89, p<.001, \eta^{2}=.154$. However, there was no statistical difference between narrative and non-narrative condition for brand attitude, $F(1,293)=.860, p$ $=.354$. Thus, $\mathrm{H} 1$ was partially supported.

H2a predicted that it would take shorter time for participants with non-narrative ad condition to recognize advertised brand comparing to narrative ad condition. To test this hypothesis, three-way analysis of variance (ANOVA) was employed. The omnibus test revealed significant main effect for ad type, $F(1,293)=4.22, p<.05, \eta^{2}=.014$. Pairwise comparison showed that respondents with non-narrative ad condition $(M=6.78$, $S D=3.64, p=.41)$ responded quicker than those who only watched narrative ad $(M=$ 
$7.69, S D=3.84, p=.41)$. The brand name recognition accuracy was $64.1 \%$ in the nonnarrative ad condition, compared with 59.2\% in the narrative-ad condition. For H2b, however, there was no significant effect from the brand name placement, $F(1,293)=.029$, $p=.865$. The result showed that there were no significant differences between participants with early condition and late condition. Also, no interactions were found between the ad type and brand name placement. Thus, only H2a was supported.

H3a predicted that when participants have positive attitude toward the brand prior to exposure to an advertisement, they would report more positive attitude toward the ad and brand when they are exposed to narrative ad with early placement condition. To test this hypothesis, three-way analysis of variance (ANOVA) was employed. The omnibus test revealed no significant main effect for prior brand attitude $\mathrm{x}$ narrative ad $\mathrm{x}$ early condition interaction on attitude toward ad, $F(1,293)=.314, p=.583$. However, as H3b predicted that there was significant interaction between prior brand attitude, narrative ad, and placement condition, $F(1,293)=4.72, p=.031, \eta^{2}=.009$. Pairwise comparison showed that respondents with negative prior brand attitude and watched narrative ad with early condition reported less positive attitude toward the brand $(M=3.92, S D=1.27, p$ $<.005)$ comparing to prior brand attitude $\mathrm{x}$ narrative ad $\mathrm{x}$ end condition $(M=5.77, S D$ $=.86, p<.005)$. Thus, $\mathrm{H} 3 \mathrm{~b}$ was partially supported. 
Table 6. Summary of ANOVA for effects of ad type, brand name placement, and prior brand attitude

\begin{tabular}{lcccccc}
\hline \multirow{2}{*}{ Source } & \multicolumn{2}{c}{ Ad attitude } & \multicolumn{2}{c}{ Brand attitude } & \multicolumn{2}{c}{ Response latency } \\
\cline { 2 - 7 } MT & $F$ & $d f$ & $F$ & $d f$ & $F$ & $d f$ \\
BP & $52.89^{* * * *}$ & 1 & 0.86 & 1 & $4.22^{*}$ & 1 \\
PA & 0.06 & 1 & $5.90^{*}$ & 1 & 0.03 & 1 \\
MT x BP & 1.56 & 1 & $189.86^{* * *}$ & 1 & 0.73 & 1 \\
MT x PA & 1.50 & 1 & 2.97 & 1 & 0.01 & 1 \\
BP $\times$ PA & 1.40 & 1 & 1.01 & 1 & 0.01 & 1 \\
MT x BP x PA & 0.29 & 1 & 0.3 & 1 & 0.25 & 1 \\
\hline
\end{tabular}

Notes: $\mathrm{MT}=$ message type, $\mathrm{BP}=$ brand name placement, $\mathrm{PA}=$ prior brand attitude $* p<.05 ; * * p<.01 ; * * * p<.001$ 


\section{CHAPTER 5: DISCUSSION}

The current research examined how brand name placement within narrative advertising influenced consumers. Previous research by Baker et al. (2004) employed different kinds of advertising to increase generalization. In contrast, the current study focused on narrative advertising and how it interacts with brand name placement. Additionally, even though the current study's design was almost identical to Baker et al.'s study, the results were not identical.

\section{Study Significance}

Much of the research that dealt with narrative advertising illustrated that people who watched a narrative advertising showed a more positive attitude than people who watched nonnarrative advertising (Chang, 2009; Escalas, 2004a; Kim et al., 2017; Mazzocco, Green, Sasota, \& Jones, 2010). Consistent with previous literature, the current research also confirmed that people who watched a narrative ad reported a more positive attitude toward the advertising compared with people who watched a nonnarrative advertising. However, unlike previous studies that showed brand attitude was higher among people exposed to narrative advertisement, the current research found no significant effect of narrative advertising on brand attitude.

As mentioned above, previous studies pointed to benefits of employing narrative advertising, such as less eliciting of counterarguments and negative emotions. Interestingly, however, the current study found that narrative advertising was not always a powerful and effective tool to persuade consumers. Additionally, this study found that narrative advertising might place a burden on information processing. People who watched narrative advertising recognized the brand more slowly than people who 
watched nonnarrative advertising. According to the network model of memory, quicker response indicates stronger association strength between the nodes. This means that people who watched the nonnarrative advertisement processed the brand information more thoroughly when compared with people exposed to the narrative advertisement. Additionally, the recognition accuracy rate was higher in the nonnarrative condition (64\%) than in the narrative condition (59\%). This finding was consistent with the study by Chang (2009), who argued that narrative features require extra cognitive resources to process information, which makes the effectiveness of narrative advertising dependent on cognitive resource availability. Thus, one of the reasons for a better accuracy rate and quicker responses among participants in the nonnarrative condition was that the nonnarrative advertising did not require as many cognitive resources to process information. Thus, nonnarrative advertising might result in better recall of brand information.

Baker et al. (2004) found that brand attitude was significantly higher when the brand name was placed at the beginning of the advertisement compared with late presentation of the brand name. The current research also found effects from brand name placement within the advertising. However, the result was in the opposite direction of what Baker et al. (2004) found in their study. The current study found that participants in the end condition reported higher brand attitude compared with the early condition. Additionally, unlike the prediction of the network model of memory, no significant difference was found between the early and late conditions on response latency. Perhaps such short exposure ( 2 seconds) of the brand was not enough time to encode and build strong associations between the brand and advertisement. 
Although previous literature has shown the influence of prior brand attitude on directionality of evaluation, the current research did not find a significant effect, except for one interaction effect on brand attitude. This lack of significance was perhaps due to the fact that the students' preference for the targeted brand was stronger than predicted.

This research provides important implications for advertising practitioners.

Practitioners may take into account results of the study when designing advertisements. Interaction of brand name placement, message type (narrative versus nonnarrative), and prior brand attitude showed significant effects on brand attitude. A person with a negative prior brand attitude was more likely to report lower brand attitude when the brand name was presented at the beginning of the advertising within the narrative. This result indicated that even if narrative advertising itself is a powerful tool to persuade consumers, it is not always effective. Perhaps this is because when people with negative brand attitude saw the target brand logo at the beginning of the advertisement, negative thoughts were activated. And if a warm and emotional tone is presented, people may realize that the advertising is not consistent with their existing belief and attitudes, which could eventually lead to lower brand attitude. For example, if the brand is experiencing turbulence (e.g., corporate crisis), the brand name would be better revealed at the end, especially when narrative advertising is employed. Although the current study did not examine how brand name placement throughout the advertising (e.g., Budweiser's Clydesdales ads) would influence consumer brand perception, placement could possibly hurt advertising effectiveness. This is because presenting a brand that is experiencing crisis throughout the advertisement could interfere with immersing consumers into the story and could elicit antipathy due to inconsistency with their previous negative brand 
belief and the tone of the advertising. Thus, future research could explore how brand integration influences brand perception.

Additionally, if a brand is trying to build a good relationship and have people like its advertisements, practitioners should consider narrative advertising because the results of this study showed that narrative advertising induces a positive evaluation of the advertising. In contrast, if a brand wants people to retain brand and advertising information, nonnarrative advertising would be more suitable because data analysis illustrated that people who view nonnarrative ads tend to recall the brand information faster and more accurately, which creates a stronger association between the brand and brand information.

\section{Limitations}

The current research has several limitations. First, even though the study used an experimental design, it was not conducted in a lab. Because it was distributed through an online survey tool, students might not have watched the stimuli thoroughly. Additionally, the response latency that is measured by Qualtrics might not be as accurate as measured in the lab, and, because response latency is measured in milliseconds, accuracy is crucial. Additionally, although the current study tried to imitate real life situation by presenting advertisements consecutively, it is unsure whether people actually stare at advertisements while they watch TV programs.

Second, even though this study chose AT\&T as the targeted brand due to high variance on evaluation, many of the college students reported positive attitudes toward the brand. Thus, the effect size of prior attitude was not as significant as expected, and, unlike past studies, prior attitude did not moderate the relationship between the variables 
as predicted. This lack of variance might occur due to the difference in age. Most of the participants of the current main study were 19 to 20 . However, people who participated in pre-test were age from 24 to 46 . There was more variance within the group. Half of the group reported that they liked AT\&T whereas rest of the group disliked the brand. Also, prior brand attitude could be depended on the area where participants live. This is because some of the town in the U.S. do not have AT\&T service, and this could be the reason why students are more leaning toward to report the prior brand attitude as neutral.

Third, the current study did not reflect real-world situations. This research employed 60-second advertisements as stimuli, instead of 30-second advertisements. Although some companies use the longer advertisements, many companies use the shorter advertisements in actual practice.

Lastly, unlike Baker et al.'s study, this study is lacked with generalization. Baker and his colleagues employed different unknown brands and different type of advertisements to increase the generalizability. However, the current study specifically used only one brand and one product category. As mentioned above, some of the students might not have experience of using AT\&T. This means that participants might report differently with the brands that they have used previously. 


\section{APPRENDICES}

\section{A. Advertisements}

- Commercial \#1- Coca Cola https://www .youtube.com/watch?v=s0brZ8Cinao

- Commercial \#2- Carlton Draught https://vimeo.com/43040167

- Commercial \#3- Chick-fil-A

A https://www.youtube.com/watch?v=bHwokaCT4kw

- Commercial \#4- Apple https://www.youtube.com/watch?v=2gHeBVyqJRo

- Commercial \#5- McDonalds https://www.youtube.com/watch?v=izzcxSL3SMk

- Narrative Ad - AT\&T https://www.youtube.com/watch?v=k0OnsDXXjQg

- Nonnarrative Ad - AT\&T https://vimeo.com/39079179

\section{B. Logo}

- https://www.youtube.com/watch?v=YmtWiNuBNQU 


\section{Study Design}

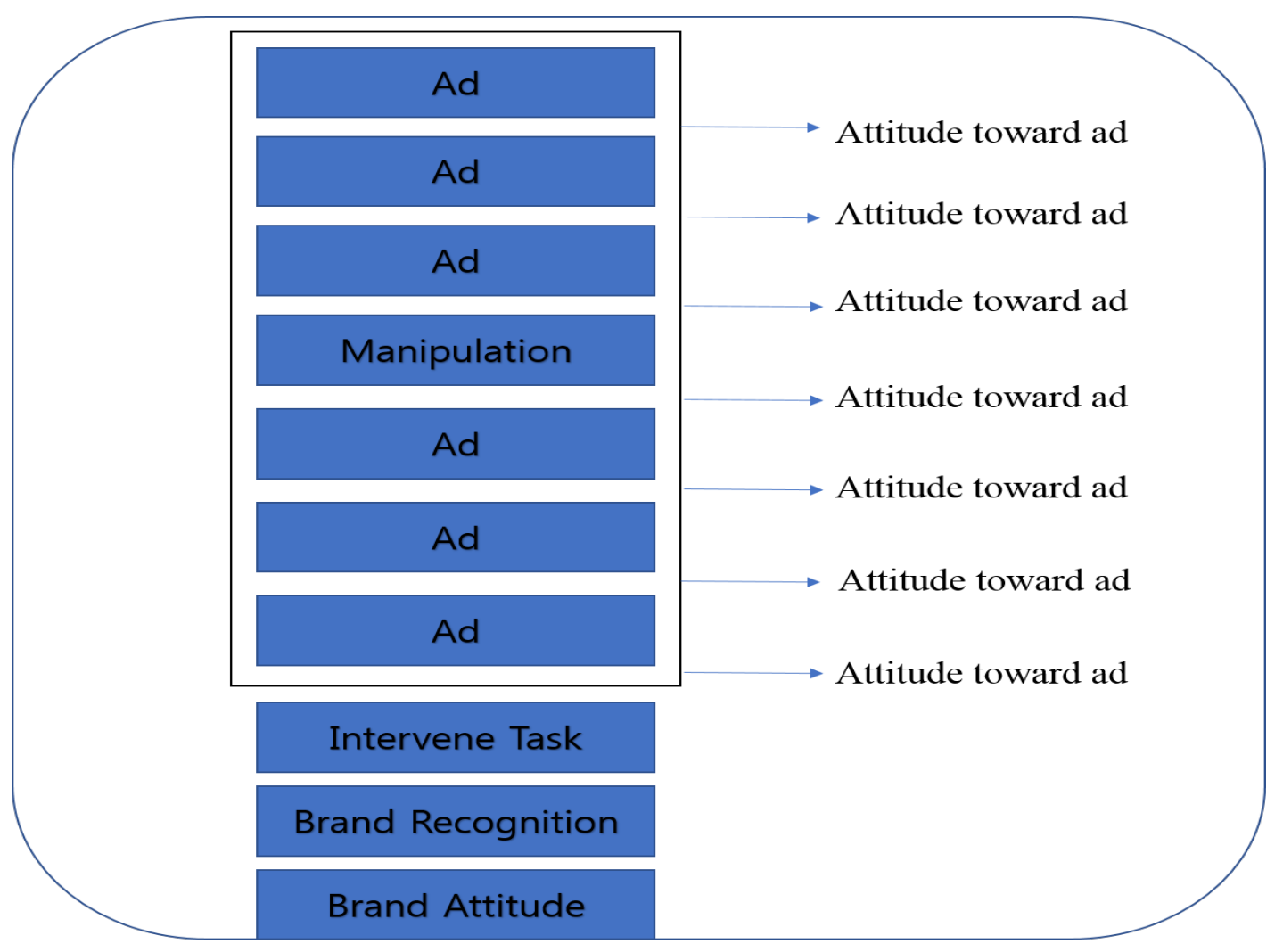

\section{Consent}

The purpose of this research study is to learn more about the influence of brand name presentation within the advertising on brand perception.

The following information is provided in order to help you make an informed decision about whether or not to participant. To be included in the study, you must meet the following criteria:

(1) At least 18 years of age

If you do not meet the above criteria, you do not qualify for this particular study and should not proceed with the survey.

Procedures: If you meet the above criteria, you may take part in a survey looking at how brand name presentation influences on brand perception.

In this survey, you will first watch an advertisement. Next, you will answer questions based on different presentations of brand name.

Confidentiality: The information investigators obtain will be kept strictly anonymous. Your responses will not be associated with you individually in any way, and your name will not be tied to any of your answers. At any point in the research process, your name 
and identity will not be linked in any way to the information you provide in the survey. We may present the research findings at professional meetings or publish the results of this research study in relevant journals. However, we will always keep your name and other identifying information private.

Benefits of Participating in the Study: There are no direct benefits to you for participating in this study except potentially contributing to research that will help better understanding of advertising design.

Risks and/or Discomfort of Participating in the Study: There are no known risks associated with this study.

Compensation for Participation: Per your instructor's discretion, you may receive 2 points of extra credit. If you feel uncomfortable to participate in the study, you may participate in doing alternate assignment. The alternate assignment consists of reading a peer reviewed article and writing a one page reflection.

Contact Information: If you have any questions concerning this research project, please feel free to contact KyungKu Lee (narrativead@gmail.com) at 573-673-4541 or Glen Cameron (camerong@missouri.edu) at 573-864-2897. Moreover, you may contact the Campus Institutional Review Board if you have questions about your rights, concern, complaints or comments as a research participant. You can contact the Campus Institutional Review Board directly by telephone or email to voice or solicit any concerns, questions, input or complaints about the research 483 McReynolds Hall Columbia, MO 65211 573-882-9585 or umcresearch@missouri.edu.

Freedom to Withdraw: Your participation in this study is voluntary. You can refuse to participate or withdraw at any time without harming your relationship with the researchers, University of Missouri, or in any other way receive a penalty or loss of benefits to which you are otherwise entitled.

What does my clicking "YES" on this form mean?

- You understand the information given to you in this form.

- You are able to ask the researcher questions and state any concerns

- The researcher will respond to your questions and concerns

- You believe you understand the research study and the potential benefits and risks that are involved

By clicking YES you agree to the information provided in the Consent Form, and will be directed to the survey

By clicking NO, you will be directed to the alternate extra credit option and out of the survey

\section{YES NO}

Investigators: Kyung Ku Lee 
Department of Journalism

University of Missouri

KLQK7@mail.missouri.edu - Kyung Ku Lee

E. IRB APPROVAL

방

Institutional Review Board University of Missouri-Columbia
190 Galena Hall; Dc074.00

Columbia, MO 65212

573-882-3181

irb@missouri.edu

March 13, 2017

Principal Investigator: Kyung Ku Lee

Department: VP for International Programs

Your Exempt Application to project entitled If you are feeling confident enough, Do not hesitate to reveal who you really are: Extension of Baker, Honea and Russell (2004) was reviewed and approved by the MU Institutional Review Board according to the terms and conditions described below:

$\begin{array}{ll}\text { IRB Project Number } & 2008091 \\ \text { IRB Review Number } & 224684\end{array}$

Initial Application Approval Date March 13, 2017

IRB Expiration Date March 13, 2018

Level of Review Exempt

Project Status Active - Open to Enrollment

Exempt Categories $\quad 45$ CFR $46.101 \mathrm{~b}(2)$

Risk Level Minimal Risk

Internal Funding Personal funds

The principal investigator (PI) is responsible for all aspects and conduct of this study. The PI must comply with the following conditions of the approval:

1. No subjects may be involved in any study procedure prior to the IRB approval date or after the expiration date.

2. All unanticipated problems and deviations must be reported to the IRB within 5 business days.

3. All changes must be IRB approved prior to implementation unless they are intended to reduce immediate risk.

4. All recruitment materials and methods must be approved by the IRB prior to being used.

5. The Annual Exempt Form must be submitted to the IRB for review and approval at least 30 days prior to the project expiration date. If the study is complete, the Completion/Withdraw al Form may be submitted in lieu of the Annual Exempt Form

6. Maintain all research records for a period of seven years from the project completion date.

7. Utilize all approved research documents located within the attached files section of eCompliance. These documents are highlighted green.

If you are offering subject payments and would like more information about research participant payments, please click here to view the MU Business Policy and Procedure: 


\section{REFERENCES}

Anderson, J. R. (1983). A spreading activation theory of memory. Journal of Verbal Learning and Verbal Behavior, 22(3), 261-295. https://doi.org/10.1016/S0022-5371(83)90201-3

Baker, W. E. (2003). Does brand name imprinting in memory increase brand information retention? Psychology and Marketing, 20(12), 1119-1135. https://doi.org/10.1002/mar.10111

Baker, W. E., Honea, H., \& Russell, C. A. (2004). DO NOT WAIT TO REVEAL THE BRAND NAME: The Effect of Brand-Name Placement on Television Advertising Effectiveness. Journal of Advertising, 33(3), 77-85. https://doi.org/10.1080/00913367.2004.10639170

Brechman, J. M., \& Purvis, S. C. (2015). Narrative, transportation and advertising. International Journal of Advertising, 34(2), 366-381. https://doi.org/10.1080/02650487.2014.994803

Bruner, J. S. (1990). Acts of Meaning. Harvard University Press.

Burke, R. R., \& Srull, T. K. (1988a). Competitive Interference and Consumer Memory for Advertising. Journal of Consumer Research, 15(1), 55-68. https://doi.org/10.1086/209145

Burke, R. R., \& Srull, T. K. (1988b). Competitive Interference and Consumer Memory for Advertising. Journal of Consumer Research, 15(1), 55-68. https://doi.org/10.1086/209145

Cacioppo, J. T., Petty, R. E., Kao, C. F., \& Rodriguez, R. (1986). Central and peripheral routes to persuasion: An individual difference perspective. Journal of Personality and Social Psychology, 51(5), 1032-1043. https://doi.org/10.1037/0022-3514.51.5.1032

Cameron, G. T., \& Frieske, D. A. (1994). The time needed to answer: Measurement of memory response latency.

Chang, C. (2009). "Being Hooked" By Editorial Content: The Implications for Processing Narrative Advertising. Journal of Advertising, 38(1), 21-34. 
https://doi.org/10.2753/JOA0091-3367380102

Chang, C. (2013). Imagery Fluency and Narrative Advertising Effects. Journal of Advertising, 42(1), 54-68. https://doi.org/10.1080/00913367.2012.749087

Chattopadhyay, A., \& Basu, K. (1990). Humor in Advertising: The Moderating Role of Prior Brand Evaluation. Journal of Marketing Research, 27(4), 466-476. https://doi.org/10.2307/3172631

Collins, A. M., \& Loftus, E. F. (1975). A spreading-activation theory of semantic processing. Psychological Review, 82(6), 407-428. https://doi.org/10.1037/0033-295X.82.6.407

Csikszentmihalyi, M., \& LeFevre, J. (1989). Optimal experience in work and leisure. Journal of Personality and Social Psychology, 56(5), 815-822. https://doi.org/10.1037/0022-3514.56.5.815

Deighton, J., Romer, D., \& McQueen, J. (1989). Using Drama to Persuade. Journal of Consumer Research, 16(3), 335-343. https://doi.org/10.1086/209219

Escalas, J. E. (2004a). IMAGINE YOURSELF IN THE PRODUCT : Mental Simulation, Narrative Transportation, and Persuasion. Journal of Advertising, 33(2), 3748. https://doi.org/10.1080/00913367.2004.10639163

Escalas, J. E. (2004b). Narrative processing: Building consumer connections to brands. Journal of Consumer Psychology, 14(1-2), 168-180. https://doi.org/10.1207/s15327663jcp1401\&2_19

Escalas, J. E., Moore, M. C., \& Britton, J. E. (2004). Fishing For Feelings? Hooking Viewers Helps! Journal of Consumer Psychology, 14(1-2), 105-114. https://doi.org/10.1207/s15327663jcp1401\&2_12

Fazio, R. H. (1990). A practical guide to the use of response latency in social psychological research (pp. 74-97).

Fiske, S. T. (1993). Social cognition and social perception. Annual Review of Psychology, 44 , 155-194. https://doi.org/10.1146/annurev.ps.44.020193.001103

Geuens, M., De Pelsmacker, P., \& Faseur, T. (2011). Emotional advertising: Revisiting 
the role of product category. Journal of Business Research, 64(4), 418-426. https://doi.org/10.1016/j.jbusres.2010.03.001

Green, M. C., \& Brock, T. C. (2000). The role of transportation in the persuasiveness of public narratives. Journal of Personality and Social Psychology, 79(5), 701721. https://doi.org/10.1037/0022-3514.79.5.701

Green, M. C., Brock, T. C., \& Kaufman, G. F. (2004). Understanding Media Enjoyment: The Role of Transportation Into Narrative Worlds. Communication Theory, 14(4), 311-327. https://doi.org/10.1111/j.1468-2885.2004.tb00317.x

Jin, C., \& Villegas, J. (2007). The effect of the placement of the product in film: Consumers' emotional responses to humorous stimuli and prior brand evaluation. Journal of Targeting, Measurement and Analysis for Marketing, 15(4), 244-255. https://doi.org/10.1057/palgrave.jt.5750049

Keller, K. L. (1987). Memory Factors in Advertising: The Effect of Advertising Retrieval Cues on Brand Evaluations. Journal of Consumer Research, 14(3), 316-333. https://doi.org/10.1086/209116

Kent, R. J., \& Allen, C. T. (1994). Competitive interference effects in consumer memory for advertising: The role of brand familiarity.

Kim, E. (Anna), Ratneshwar, S., \& Thorson, E. (2017). Why Narrative Ads Work: An Integrated Process Explanation. Journal of Advertising, O(0), 1-14. https://doi.org/10.1080/00913367.2016.1268984

Lang, A. (2000). The limited capacity model of mediated message processing. Journal of Communication, 50(1), 46-70. https://doi.org/10.1111/j.14602466.2000.tb02833.

Lang, A. (2006). Using the Limited Capacity Model of Motivated Mediated Message Processing to Design Effective Cancer Communication Messages. Journal of Communication, 56, S57-S80. https://doi.org/10.1111/j.14602466.2006.00283.

Lang, A., Geiger, S., Strickwerda, M., \& Sumner, J. (1993). The effects of related and unrelated cuts on television viewers' attention, processing capacity, and memory. Communication Research, 20(1), 4-29. https://doi.org/10.1177/009365093020001001 
Madden, T., \& Weinberger, M. (1984). Humor in advertising: A practitioner view. Journal of Advertising Research. Retrieved from https://www.researchgate.net/publication/303156202_Humor_in_advertisi ng_A_practitioner_view

Mazzocco, P. J., Green, M. C., Sasota, J. A., \& Jones, N. W. (2010). This Story Is Not for Everyone: Transportability and Narrative Persuasion. Social Psychological and Personality Science, 1(4), 361-368. https://doi.org/10.1177/1948550610376600

Nakamura, J., \& Csikszentmihalyi, M. (2014). The Concept of Flow. In Flow and the Foundations of Positive Psychology (pp. 239-263). Springer Netherlands. Retrieved from http://link.springer.com/chapter/10.1007/978-94-0179088-8_16

Neff, J. (2014, January 6). Study: 80\% of Super Bowl Ads Don't Help Sales. Ads in Big Game Fare Worse Than Others As Brand Recall Lags. Retrieved October 28, 2015, from http://adage.com/article/special-report-super-bowl/study-80super-bowl-ads-sales/290907/

Petty, R. E., \& Cacioppo, J. T. (1986). The Elaboration Likelihood Model of Persuasion. In Communication and Persuasion (pp. 1-24). Springer New York. Retrieved from http://link.springer.com/chapter/10.1007/978-1-4612-4964-1_1

Roediger III, H. L., Balota, D. A., \& Watson, J. M. (2001). Spreading activation and arousal of false memories.

Schank, R. C., \& Abelson, R. P. (1995). Knowledge and Memory: The Real Story. In R. S. Wyer (Ed.), Knowledge and Memory: The Real Story (pp. 1-85). Lawrence Erlbaum Associates. Retrieved from http://cogprints.org/636/

Sebastian, M. (2015, March 25). Marketers to Boost Global Ad Spending This Year to $\$ 540$ Billion. Retrieved October 31, 2015, from http://adage.com/article/media/marketers-boost-global-ad-spending-540billion/297737/

Sterling, G. (2015, January 30). Massive Exposure, Minimal Impact: Doubts About Super Bowl Ad Effectiveness. Retrieved February 19, 2017, from http://marketingland.com/massive-exposure-minimal-impact-doubts-superbowl-ad-effectiveness-116572 
Weinberger, M. G., \& Gulas, C. S. (1992). The Impact of Humor in Advertising: A Review. Journal of Advertising, 21(4), 35-59. https://doi.org/10.1080/00913367.1992.10673384

Yoon, K., Bolls, P., \& Lang, A. (1998). The effects of arousal on liking and believability of commercials. Journal of Marketing Communications, 4(2), 101-114. https://doi.org/10.1080/13527269800000003 